\title{
On the role of cannabinoid CB1- and $\mu$-opioid receptors in motor impulsivity
}

\section{Joost Wiskerke, Yvar van Mourik, Dustin Schetters, Anton N. M. Schoffelmeer and Tommy Pattij*}

Department of Anatomy and Neurosciences, Neuroscience Campus Amsterdam, VU University Medical Center, Amsterdam, The Netherlands

Edited by:

Joseph F. Cheer, University of

Maryland School of Medicine, USA

\section{Reviewed by:}

Muzamil Ahmad, Indian Institute of

Integrative Medicine, India

Marcello Solinas, Institut National de

la Santé et la Recherche Medicale,

France

\section{*Correspondence.}

Tommy Pattij, Department of

Anatomy and Neurosciences,

Neuroscience Campus Amsterdam,

VU University Medical Center, Van der

Boechorststraat 7, 1081 BT

Amsterdam, The Netherlands.

e-mail: t.pattij@vumc.n!
Previous studies using a rat 5 -choice serial reaction time task have established a critical role for dopamine D2 receptors in regulating increments in motor impulsivity induced by acute administration of the psychostimulant drugs amphetamine and nicotine. Here we investigated whether cannabinoid CB1 and/or $\mu$-opioid receptors are involved in nicotineinduced impulsivity, given recent findings indicating that both receptor systems mediate amphetamine-induced motor impulsivity. Results showed that the cannabinoid CB1 receptor antagonist SR141716A, but not the opioid receptor antagonist naloxone, reduced nicotine-induced premature responding, indicating that nicotine-induced motor impulsivity is cannabinoid, but not opioid receptor-dependent. In contrast, SR141716A did not affect impulsivity following a challenge with the dopamine transporter inhibitor GBR 12909, a form of drug-induced impulsivity that was previously found to be dependent on $\mu$-opioid receptor activation. Together, these data are consistent with the idea that the endogenous cannabinoid, dopamine, and opioid systems each play important, but distinct roles in regulating (drug-induced) motor impulsivity. The rather complex interplay between these neurotransmitter systems modulating impulsivity will be discussed in terms of the differential involvement of mesocortical and mesolimbic neurocircuitry.

Keywords: 5-choice serial reaction time task, endocannabinoid system, endogenous opioid system, inhibitory response control, mesocortical dopamine system, mesolimbic dopamine system, nicotine, rat

\section{INTRODUCTION}

Impulsivity is a multifaceted construct covering various, largely independent, behavioral measures including inhibitory control or motor impulsivity, i.e., the inability to restrain inappropriate behavior (Evenden, 1999; Winstanley et al., 2006; Pattij and Vanderschuren, 2008; Broos et al., 2012). There is considerable evidence in human and rodent literature for a link between maladaptive display of various types of impulsive behaviors and abuse of/addiction to different classes of drugs of abuse. The direction of this interaction is likely to be bidirectional, with heightened levels of impulsivity predisposing individuals for display of addictive behaviors and exposure to addictive substances increasing display of impulsive behaviors (Jentsch and Taylor, 1999; Perry and Carroll, 2008; Verdejo-Garcia et al., 2008; Winstanley et al., 2010a). A common effect of acute administration of addictive substances such as psychostimulants, opiates, and alcohol in rodents is an increase in motor impulsivity (Cole and Robbins, 1987; van Gaalen et al., 2006; Olmstead et al., 2009; Pattij et al., 2009), reflected in an increase in premature responding in, e.g., the 5choice serial reaction time task (5-CSRTT; Robbins, 2002). This commonality between different types of drugs of abuse may be related to their shared ability to increase dopamine release in the brain (Di Chiara and Imperato, 1988; Sulzer, 2011). There are three anatomically segregated, but heavily interacting dopaminergic circuitries in the brain; the nigrostriatal, the mesolimbic, and the mesocortical dopamine systems (Ungerstedt, 1971; Fallon and Moore, 1978; Goto and Grace, 2007). Particularly the mesolimbic and mesocortical systems, comprising projections from the ventral tegmental area to respectively limbic structures like the nucleus accumbens and frontal cortical areas, are thought to regulate motor impulsivity in humans and rodents (Pattij and Vanderschuren, 2008; Dalley et al., 2011; Winstanley, 2011). In this respect, most studies on amphetamine-induced motor impulsivity revealed an important role for the mesolimbic dopamine system, and more specifically dopamine signaling and dopamine D2 receptor activity in the nucleus accumbens (Cole and Robbins, 1987, 1989; Pattij et al., 2007b).

Recently, other neurotransmitter systems have also been implicated in amphetamine-induced motor impulsivity. For instance, antagonists of the cannabinoid CB1 receptor and $\mu$-opioid receptor have been found to suppress the impulsivity-related effects of amphetamine in the 5-CSRTT (Wiskerke et al., 2011a,b), possibly via interactions with dopaminergic systems (Wiskerke et al., 2011a; Kleijn et al., 2012). As to whether or not these cannabinoid and opioid mechanisms generalize to other drugs of abuse remains to be determined. In this regard, the psychostimulant drug nicotine is of particular interest. Tobacco smoking is a major global health problem causing a large financial burden for society. There is a wealth of evidence from human and rodent studies indicating a reciprocal link between impulsivity and nicotine abuse (Bickel et al., 1999; Mitchell, 2004; Doran et al., 2007; Diergaarde et al., 2008, 2011; Counotte et al., 2009). Acute challenges with nicotine induce inhibitory control deficits in the 5-CSRTT via stimulation of nicotinic receptors, particularly $\alpha_{4} \beta_{2}$-receptors in 
the infralimbic cortex (Blondel et al., 2000; Grottick and Higgins, 2000; Tsutsui-Kimura et al., 2010). However, as for amphetamine, nicotine-induced increments in motor impulsivity have been reported to additionally depend on dopamine D2 receptor and serotonin $5-\mathrm{HT}_{2 \mathrm{c}}$ receptor activity (van Gaalen et al., 2006; Fletcher et al., 2011; Higgins et al., 2012). Thus, and since there is ample evidence for an important role for cannabinoid CB1 and $\mu$-opioid receptors in other nicotine-induced behaviors (Berrendero et al., 2010; Hadjiconstantinou and Neff, 2011; Serrano and Parsons, 2011), the aim of the current study was to examine whether cannabinoid $\mathrm{CB} 1$ and $\mu$-opioid receptors mediate nicotine-induced motor impulsivity.

\section{MATERIALS AND METHODS SUBJECTS}

Male Wistar rats were obtained from Harlan CPB (Horst, The Netherlands). At the start of the experiments animals weighed approximately 250 grams, and were housed two per cage in macrolon cages $(42.5 \mathrm{~cm} \times 26.6 \mathrm{~cm} \times 18.5 \mathrm{~cm}$; length $\times$ width $\times$ height) under a reversed $12 \mathrm{~h}$ light/dark cycle (lights on at $7.00 \mathrm{pm})$ at controlled room temperature $\left(21 \pm 2^{\circ} \mathrm{C}\right)$ and relative humidity of $60 \pm 15 \%$. Animals were maintained at approximately $90 \%$ of their free-feeding weight, starting 1 week prior to the beginning of the experiments by restricting the amount of standard rodent food pellets (Harlan Teklad Global Diet, Blackthorn, UK). Water was available ad libitum throughout the entire experiment. All experiments were conducted with the approval of the animal ethical committee of the VU University Amsterdam, The Netherlands, and all efforts were made to minimize animal suffering.

\section{DRUGS}

SR141716A was generated and kindly provided by Abbott (Weesp, The Netherlands) and dissolved in a mixture of ethanol, Tween 80, and sterile saline (ratio 1:1:18). Naloxone hydrochloride, nicotine hydrogen tartrate, and $S(-)$ eticlopride hydrochloride (all Sigma Aldrich, St. Louis, MO, USA) were dissolved in sterile saline, whereby it should be noted that the $\mathrm{pH}$ was neutralized for nicotine after dissolving the salt. 1-(2-[Bis(4-fluorophenyl)methoxy]ethyl)-4-(3phenylpropyl) piperazine dihydrochloride (GBR 12909 dihydrochloride; Sigma Aldrich) was dissolved in sterile water. Drug doses (calculated as salts) and injection times were based on previous 5-CSRTT studies in our laboratory (van Gaalen et al., 2006; Pattij et al., 2007a, 2009; Wiskerke et al., 2011a,b). SR141716A was injected $45 \mathrm{~min}$ prior to testing, naloxone, and eticlopride $30 \mathrm{~min}$ prior to testing, and GBR 12909 and nicotine $20 \mathrm{~min}$ prior to testing. Drugs were freshly prepared on each test day and injected intraperitoneally (i.p.), with an exception for nicotine which was administered subcutaneously (s.c.), in a volume of $1 \mathrm{ml} / \mathrm{kg}$ bodyweight according to a Latin square within subjects design. Drug tests were conducted on Tuesdays and Fridays with baseline training sessions on the other weekdays. Prior to the first test day, all animals had been habituated twice to i.p. and/or s.c. saline injections.

\section{APPARATUS}

Experiments were conducted in identical rat five hole nose poke operant chambers with stainless steel grid floors (MED-NPW-
5L, Med Associates Inc., St. Albans, VT, USA) housed in soundinsulating and ventilated cubicles. Set in the curved wall of each box was an array of five holes. Each nose poke unit was equipped with an infrared detector and a yellow light emitting diode (LED) stimulus light. Rodent food pellets ( $45 \mathrm{mg}$, Formula P, Bio-Serv, Frenchtown, NJ, USA) could be delivered at the opposite wall via a dispenser. In addition, a white house light could illuminate the chamber. A computer equipped with MED-PC version 1.17 (Med Associates Inc.) controlled experimental sessions and recorded data. Animals were tested once daily from Monday until Friday, during the dark phase of the light/dark cycle.

\section{BEHAVIORAL PROCEDURES}

Separate groups of animals $(n=14-16)$ were trained for each experiment involving a different drug (combination), unless stated otherwise. Importantly, each rat was trained in the same operant chamber for the entire experiment. Prior to the 5-CSRTT, animals were subjected to habituation and magazine training protocols. This protocol consisted of a habituation exposure to the operant chambers for $20 \mathrm{~min}$ with the house light on and the food cup containing three food pellets during the first session. Subsequently, in the next two sessions, in total 75 pellets were delivered with an average delay of $15 \mathrm{~s}$ to allow the animals to associate the sound of pellet delivery with reward.

\section{5-CHOICE SERIAL REACTION TIME TASK}

A detailed description of the 5-CSRTT behavioral procedure in our laboratory has been provided previously (van Gaalen et al., 2006). In short, rats were trained to detect and respond to a brief visual stimulus in one of 5 nose poke units in order to obtain a food reward. Each session terminated after 100 trials or $30 \mathrm{~min}$, whichever occurred first. Initially the duration of this stimulus was $32 \mathrm{~s}$ and was gradually decreased to $1 \mathrm{~s}$ over sessions until animals reached stable baseline performance (accuracy $>80 \%$ correct choice and $<20 \%$ errors of omission). Responding during stimulus presentation or within the limited hold ( $\mathrm{LH})$ period of $2 \mathrm{~s}$ was counted as a correct response. Incorrect responses, premature responses during the fixed $5 \mathrm{~s}$ intertrial interval (ITI), and errors of omission (no response during stimulus presentation or subsequent LH) did not lead to the delivery of a food reward and resulted in a 5-s time-out period during which the house light was extinguished. Importantly, when drug effects were studied under conditions with lengthened ITI duration, only for those specific test days, a fixed $7 \mathrm{~s}$ ITI was used. Perseverative responses after correct choice, i.e., repeated responding during stimulus presentation into any stimulus unit following correct stimulus detection and before pellet collection, were measured but did not have any programmed consequences. The number of premature responses was used as an index for inhibitory control. In addition, the following other behavioral parameters were measured that reflect task performance: (1) accurate choice, i.e., percentage correct responses calculated as [number correct trials/(correct + incorrect trials) $* 100$; (2) omission errors, i.e., the total number of omitted trials during a session and; (3) the total number of perseverative responses after correct choice, measuring aspects of compulsive behavior (Robbins, 2002); (4) latency to make a correct choice, i.e., the mean time between stimulus onset and nose poke in the 
illuminated unit; and (5) feeder latency, i.e., the latency to collect a pellet following correct choice.

\section{STATISTICAL ANALYSES}

All data were analyzed using NCSS2007 version 07.1.18 (NCSS, LLC., Kaysville, UT, USA). Data were subjected to repeated measures analyses of variance (ANOVAs) with drug treatment as within subjects variable, except for 5-CSRTT experiments involving lengthened ITI duration. In that case, data were subjected to two-way ANOVAs with drug treatment and ITI duration as within subjects variables. When appropriate, homogeneity of variance across groups was determined using Mauchly's tests for equal variances, and in case of violation of homogeneity, HuynhFeldt epsilon $(\varepsilon)$ adjusted degrees of freedom were applied and the resulting more conservative probability values depicted and used for subsequent analyses. In case of statistically significant main effects, further post hoc comparisons were conducted using Newman-Keuls multiple comparison tests. The level of probability for statistically significant effects was set at 0.05. All graphs were produced using GraphPad Prism version 5.02 for Windows (GraphPad Software, San Diego, CA, USA).

\section{RESULTS}

\section{ENDOGENOUS CANNABINOIDS MODULATE NICOTINE-, BUT NOT GBR 12909-INDUCED MOTOR IMPULSIVITY}

It has previously been shown that both the psychostimulants amphetamine and nicotine induce increments in motor impulsivity in rats via a dopamine $\mathrm{D} 2$ and serotonin $5-\mathrm{HT}_{2 \mathrm{c}}$ receptordependent mechanism (van Gaalen et al., 2006; Pattij et al., 2007b; Fletcher et al., 2011; Higgins et al., 2012). Moreover, amphetamine-induced premature responding in the 5-CSRTT has been reported to be cannabinoid CB1 receptor-dependent (Wiskerke et al., 2011b). Here we determined whether CB1 receptor activation also plays a role in nicotine-induced motor impulsivity by examining the effects of the selective cannabinoid CB1 receptor antagonist SR141716A $\left(K_{\mathrm{i}}\right.$ values of $1.8-$ 12.3 and $514-13200 \mathrm{nM}$ for respectively cannabinoid $\mathrm{CB} 1$ and CB2 receptors; Pertwee, 2010) pretreatment on nicotine-induced impulsivity in the 5-CSRTT. Two rats had to be removed from analysis due to technical problems on one of the test days. In line with previous reports (van Gaalen et al., 2006; TsutsuiKimura et al., 2010; Higgins et al., 2012), acute administration of $0.3 \mathrm{mg} / \mathrm{kg}$ nicotine increased premature responding (Figure 1A; $\left.F_{5,65}=5.20, p=0.006, \varepsilon=0.54\right)$. Although not quite significant as compared to nicotine alone, prior SR141716A administration completely prevented nicotine-induced increases in premature responding. Specifically, detailed analysis showed that $3 \mathrm{mg} / \mathrm{kg}$ SR141716A + nicotine tended $(p<0.1)$ to lower the amount of premature responses made as compared to treatment with nicotine alone. SR141716A alone did not affect premature responding at any dose, thereby contrasting an initial study on the effects of this compound on premature responding in rats (Pattij et al., 2007a). This apparent discrepancy is probably related to a floor effect as discussed previously (Wiskerke et al., 2011b). As summarized in Table 1, an additional significant treatment effect was observed for errors of omission $\left(F_{5,65}=4.66, p=0.008, \varepsilon=0.57\right)$, with nicotine decreasing the number of omissions made and $3 \mathrm{mg} / \mathrm{kg}$
SR141716A reversing this effect while enhancing the omission rate when administered alone. Moreover, a significant treatment effect was observed with respect to correct response latencies $\left(F_{5,65}=5.31, p<0.001\right)$, with $3 \mathrm{mg} / \mathrm{kg}$ SR141716A by itself and in combination with nicotine increasing latencies as compared to vehicle and nicotine alone conditions, respectively. No significant effects of any treatment combination were observed on accurate choice $\left(F_{5,65}=2.12, p=0.07\right)$, perseverative responding $\left(F_{5,65}=0.67, \mathrm{NS}\right)$, or feeder latency $\left(F_{5,65}=1.09\right.$, NS, $\left.\varepsilon=0.26\right)$.

Interestingly, recent in vivo microdialysis results have suggested that a cannabinoid-dopamine interaction may be involved in the behavioral effects of amphetamine, as SR141716A was found to abolish amphetamine-induced dopamine release specifically in the nucleus accumbens shell (Kleijn et al., 2012). To study a putative cannabinoid-dopamine interaction underlying motor impulsivity, the effects of the selective dopamine transporter inhibitor GBR 12909, alone and in combination with SR141716A, were tested next in the 5-CSRTT using the rats from the nicotine-SR141716A experiment. This time one rat had to be excluded due to a technical failure on one of the test days. As previously shown (van Gaalen et al., 2006; Baarendse and Vanderschuren, 2012), administration of GBR 12909 acutely increased premature responding (Figure 1B; $F_{5,70}=6.00, p<0.001, \varepsilon=0.73$ ). Post hoc analyses showed that prior administration of 1 or $3 \mathrm{mg} / \mathrm{kg}$ SR141716A did not affect this GBR 12909 effect, nor did these doses of SR141716A by themselves affect premature responding. As summarized in Table 1, significant treatment effects were additionally observed on accurate choice $\left(F_{5,70}=3.08, p=0.01\right)$ and errors of omission $\left(F_{5,70}=6.00, p<0.001\right)$, with $3 \mathrm{mg} / \mathrm{kg}$ SR141716A alone and in combination with $5 \mathrm{mg} / \mathrm{kg}$ GBR 12909 slightly reducing the percentage of correct choices and increasing the number of omissions made. Moreover, a significant increase in latency to make a correct response was observed after administration of $3 \mathrm{mg} / \mathrm{kg}$ SR141716A by itself $\left(F_{5,70}=3.34, p=0.009\right)$. No significant effects of any treatment combination were observed for perseverative responses $\left(F_{5,70}=0.38, \mathrm{NS}\right)$ or feeder latency $\left(F_{5,70}=0.87\right.$, NS, $\left.\varepsilon=0.28\right)$.

\section{NO ROLE FOR ENDOGENOUS OPIOIDS IN REGULATING MOTOR IMPULSIVITY FOLLOWING A NICOTINE CHALLENGE OR UNDER CONDITIONS OF HEIGHTENED COGNITIVE LOAD}

The finding that the CB1 receptor plays a critical role in amphetamine- and nicotine-, but not GBR 12909-induced impulsive behavior is intriguing in view of findings demonstrating that the impulsivity effects of all three compounds are known to be mediated by the dopamine system (van Gaalen et al., 2006). A receptor system that was recently found to modulate dopamineinduced impulsive responding in the 5-CSRTT is the $\mu$-opioid receptor system (Wiskerke et al., 2011a). In that study it was found that blockade of $\mu$-opioid receptors, particularly those expressed in the nucleus accumbens shell, with either the opioid receptor antagonist naloxone or the selective $\mu$-opioid receptor antagonist CTAP suppressed amphetamine-induced premature responding. Moreover, pretreatment with naloxone abolished GBR 12909-induced impulsive behavior in the 5-CSRTT. These observations raise the question whether opioid receptors also mediate nicotine-induced impulsivity. To test this hypothesis, the effects of nicotine, alone in and in combination with naloxone 


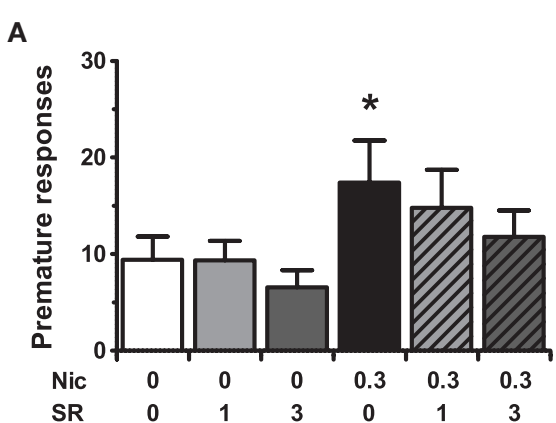

FIGURE 1 | Pretreatment with the CB1 receptor antagonist SR141716A prevents motor impulsivity induced by the psychostimulant nicotine, but not the dopamine transporter inhibitor GBR 12909. Effects of acute administration of $0.3 \mathrm{mg} / \mathrm{kg}$ nicotine [NIC (A)] or $5 \mathrm{mg} / \mathrm{kg}$ GBR 12909 [GBR
B

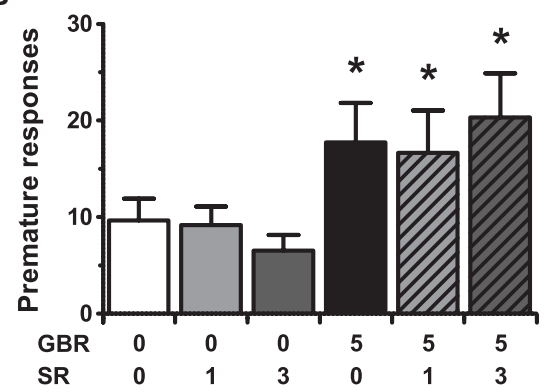

(B)], alone and in combination with SR141716A (SR), on the mean ( \pm SEM) number of premature responses made in the 5-CSRTT. In total $n=14-15$ rats were included in the analyses. Drug doses are expressed as mg/kg. $* p<0.05$ versus Vehicle-Vehicle control.

Table 1 | Effects of the psychostimulant nicotine (NIC) and the selective dopamine transporter inhibitor GBR 12909 (GBR), alone and in combination with the selective CB1 receptor antagonist SR141716A (SR) on measures of attentional function, compulsivity, and motivation in the 5-CSRTT.

\begin{tabular}{|c|c|c|c|c|c|}
\hline Treatment $(\mathbf{m g} / \mathbf{k g})$ & Accuracy $(\%)$ & Perseverative responses & Correct response latency (ms) & Omissions & Feeder latency (ms) \\
\hline Vehicle - Vehicle & $92.7 \pm 1.3$ & $8.5 \pm 2.1$ & $570 \pm 16$ & $8.2 \pm 1.7$ & $1399 \pm 81$ \\
\hline Vehicle - SR 3 & $89.6 \pm 1.9$ & $10.6 \pm 3.3$ & $622 \pm 23^{*}$ & $14.1 \pm 2.4$ & $1534 \pm 124$ \\
\hline NIC 0.3 -Vehicle & $89.2 \pm 2.1$ & $8.1 \pm 1.9$ & $547 \pm 17$ & $4.1 \pm 0.7$ & $1351 \pm 72$ \\
\hline NIC 0.3 - SR 1 & $87.9 \pm 2.1$ & $9.4 \pm 2.6$ & $579 \pm 18$ & $8.5 \pm 1.4$ & $1542 \pm 135$ \\
\hline \multicolumn{6}{|c|}{ GBR 12909 + SR141716A } \\
\hline Vehicle - Vehicle & $92.9 \pm 1.2$ & $8.9 \pm 2.0$ & $570 \pm 15$ & $8.0 \pm 1.6$ & $1429 \pm 81$ \\
\hline Vehicle - SR 1 & $89.5 \pm 1.4$ & $10.1 \pm 2.4$ & $593 \pm 16$ & $11.6 \pm 2.4$ & $2048 \pm 579$ \\
\hline Vehicle - SR 3 & $88.8 \pm 1.8$ & $11.0 \pm 3.1$ & $621 \pm 21^{*}$ & $13.5 \pm 2.3^{*}$ & $1677 \pm 184$ \\
\hline GBR 5 - Vehicle & $89.1 \pm 1.9$ & $10.8 \pm 1.8$ & $568 \pm 14$ & $6.3 \pm 1.1$ & $1615 \pm 124$ \\
\hline GBR 5 - SR 1 & $89.2 \pm 1.8$ & $10.4 \pm 1.7$ & $577 \pm 19$ & $8.3 \pm 1.8$ & $1511 \pm 95$ \\
\hline
\end{tabular}

In total $n=15$ and 14 rats were included in the analyses for nicotine-SR141716A and GBR 12909-SR141716A, respectively, and data depict mean \pm SEM.

${ }^{*} p<0.05$ and ${ }^{*} p<0.005$ versus respective Vehicle-Vehicle; ${ }^{*} p<0.05$ and ${ }^{\# \#} p<0.005$ versus Nicotine-Vehicle or GBR $12909-V e h i c l e$.

( $K_{\mathrm{i}}$ values of $\sim 0.4, \sim 6$, and $\sim 31 \mathrm{nM}$ for respectively $\mu-, \kappa-$, and $\delta$-opioid receptors (Goldstein and Naidu, 1989)) were tested in the 5-CSRTT. Results suggested that endogenous opioids are not involved in nicotine-induced impulsivity, because pretreatment with naloxone did not affect nicotine-induced premature responding (Figure 2; $F_{3,45}=8.18, p<0.001$ ). As shown in Table 2, the only other significant effect of drug treatment in this experiment was on perseverative responding $\left(F_{3,45}=3.48, p=0.04, \varepsilon=0.79\right)$, with the combination of $0.3 \mathrm{mg} / \mathrm{kg}$ nicotine $+3 \mathrm{mg} / \mathrm{kg}$ naloxone significantly decreasing the number of perseverative responses made as compared to vehicle condition. Other behavioral parameters were not affected by nicotine or naloxone (accurate choice: $F_{3,45}=1.82$, NS; correct response latency: $F_{3,45}=0.49$, NS; errors of omission: $F_{3,45}=1.34$, NS; feeder latency: $F_{3,45}=0.98$, NS).

A possible explanation for the lack of effect of naloxone on nicotine-induced motor impulsivity would be that the inhibitory control-promoting effects of naloxone are rate-dependent, and can only be observed when rats display higher levels of premature responding. One way to determine rate-dependency of a compound's effects on 5-CSRTT behavior is to compare that compound's effects under baseline conditions (ITI of $5 \mathrm{~s}$, stimulus duration of $1 \mathrm{~s}$ ) with its effects under conditions of heightened cognitive load, e.g., with a lengthened (7 s) ITI duration. The latter procedural manipulation is known to robustly increase impulsivity in the 5-CSRTT in a baseline-dependent way (Dalley et al., $2005,2007)$. Via such an experiment, the effects of SR141716A on premature responding were recently suggested to be ratedependent (Wiskerke et al., 2011b). Although the previous finding that naloxone effectively suppressed the relatively small increase in premature responding induced by a challenge injection with GBR 12909 (Wiskerke et al., 2011a) already made rate-dependency unlikely to have been a confounding factor in the nicotine- 
naloxone experiment, this explanation was further ruled out by testing the effects of naloxone under baseline ITI $(5 \mathrm{~s})$ and long ITI ( $7 \mathrm{~s}$ ) conditions. Indeed, $1 \mathrm{mg} / \mathrm{kg}$ naloxone did not affect premature responding under either condition (Figure 3; Treatment: $F_{1,15}=1.50$, NS; ITI: $F_{1,15}=43.17, p<0.001$; Treatment $\times$ ITI: $\left.F_{1,15}=0.27, \mathrm{NS}\right)$. In fact, this dose of naloxone did not affect any behavioral parameter measured (Table 3), while lengthening the ITI duration did affect accurate choice (Treatment: $F_{1,15}=2.13$, NS; ITI: $F_{1,15}=9.91, p=0.007$; Treatment $\times$ ITI: $F_{1,15}=1.00$, NS), perseverative responding (Treatment: $F_{1,15}=0.55$, NS; ITI: $F_{1,15}=6.39, p=0.023$; Treatment $\times$ ITI: $\left.F_{1,15}=0.06, \mathrm{NS}\right)$, and correct response latencies (Treatment: $F_{1,15}=0.05$, NS; ITI: $F_{1,15}=5.52, p=0.033$; Treatment $\times$ ITI: $\left.F_{1,15}=0.22, \mathrm{NS}\right)$, but not errors of omission (Treatment: $F_{1,15}=4.38, p=0.05$; ITI: $F_{1,15}=0.00$, NS; Treatment $\times$ ITI: $F_{1,15}=0.42$, NS) or feeder latencies (Treatment: $F_{1,15}=0.07, \mathrm{NS}$; ITI: $F_{1,15}=2.04$, NS; Treatment $\times$ ITI: $\left.F_{1,15}=1.86, \mathrm{NS}\right)$. Of note, similar results with respect to motor impulsivity were obtained for $3 \mathrm{mg} / \mathrm{kg}$ naloxone in a separate cohort of rats, although this dose of naloxone tended to result in additional subtle, non-specific behavioral effects (data not shown).

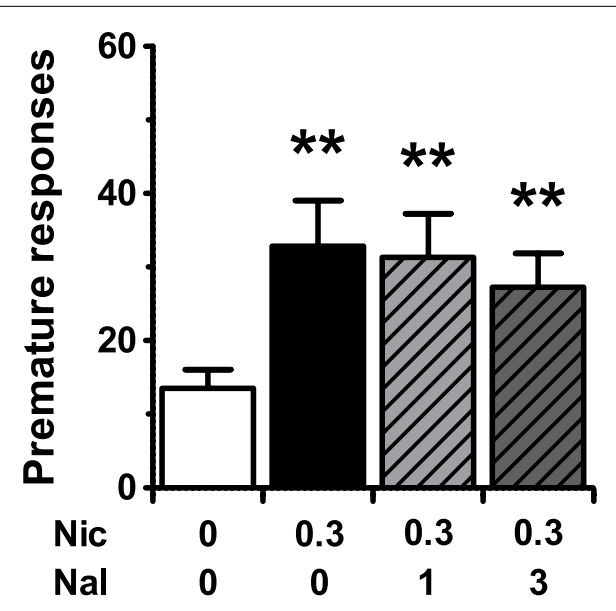

FIGURE 2 | Pretreatment with the opioid receptor antagonist naloxone does not affect motor impulsivity induced by the psychostimulant nicotine. Effects of naloxone (NAL) on the mean ( \pm SEM) number of premature responses made in the 5-CSRTT following a challenge injection with $0.3 \mathrm{mg} / \mathrm{kg}$ nicotine $(\mathrm{NIC})$. In total $n=16$ rats were included in the analyses. Drug doses are expressed as $\mathrm{mg} / \mathrm{kg}$. ${ }^{* *} p<0.005$ versus Vehicle-Vehicle control.

\section{DISCUSSION}

Previous studies have established important roles for the cannabinoid, dopamine, and opioid systems in regulating the effects of the psychostimulant drug amphetamine on motor impulsivity as measured in the 5-CSRTT (Cole and Robbins, 1987, 1989; van Gaalen et al., 2006; Wiskerke et al., 2011a,b). In the present study, we examined whether this also holds true for the psychostimulant nicotine. Results showed that the cannabinoid CB1 receptor antagonist SR141716A reduced premature responding following a challenge with nicotine, but not the dopamine transporter inhibitor GBR 12909. In contrast to SR141716A, the opioid receptor antagonist naloxone did not affect motor impulsivity induced by nicotine, nor did pretreatment with this antagonist affect premature responding under baseline ( $5 \mathrm{~s}$ ) or lengthened (7s) ITI conditions. Together, these findings indicate that endogenous cannabinoids, but not opioids, mediate nicotine-induced inhibitory control deficits, thereby extending the current knowledge on the role of cannabinoids and opioids in nicotine-induced behaviors (Berrendero et al., 2010; Hadjiconstantinou and Neff, 2011; Serrano and Parsons, 2011). The current data are only partly in line with previous findings on amphetamine-induced impulsivity (Wiskerke et al., 2011a,b), suggesting that distinct mechanisms underlie the effects of drugs of abuse. Furthermore, the current data underscore the complex interplay between the cannabinoid, dopamine, and opioid systems in regulating motor impulsivity.

\section{CANNABINOID-DOPAMINE INTERACTIONS UNDERLYING MOTOR IMPULSIVITY REVISITED}

Endogenous cannabinoid CB1 receptor activity appears to facilitate motor impulsivity as measured in the 5-CSRTT, while exogenous $\mathrm{CB} 1$ receptor agonists are ineffective in this respect (Pattij et al., 2007a; de Bruin et al., 2011; Wiskerke et al., 2011b). Similarly, the importance of dopamine signaling in regulating motor impulsivity is well known (Pattij and Vanderschuren, 2008; Dalley et al., 2011; Winstanley, 2011). Based on a large literature on reciprocal cannabinoid-dopamine interactions in the brain (Tanda et al., 1997; Solinas et al., 2008; El Khoury et al., 2012) it could be speculated that cannabinoids and dopamine communally regulate impulsive responses. In support of this, previous studies using experimental conditions similar to those of the current study have demonstrated SR141716A-mediated attenuation of amphetamine-induced premature responding in the 5-CSRTT (Wiskerke et al., 2011b) and dopamine release in the nucleus accumbens shell, but not the nucleus accumbens core or medial

Table 2 | Effects of the opioid receptor antagonist naloxone (NAL) on measures of attentional function, compulsivity, and motivation in the 5-CSRTT following a challenge injection with the psychostimulant nicotine (NIC).

\begin{tabular}{|c|c|c|c|c|c|}
\hline Treatment (mg/kg) & Accuracy (\%) & Perseverative responses & Correct response latency (ms) & Omissions & Feeder latency (ms) \\
\hline Vehicle - Vehicle & $85.4 \pm 1.5$ & $12.3 \pm 3.5$ & $589 \pm 21$ & $8.8 \pm 0.7$ & $1805 \pm 181$ \\
\hline NIC 0.3 - Vehicle & $83.3 \pm 1.3$ & $7.3 \pm 2.4$ & $580 \pm 15$ & $6.8 \pm 1.0$ & $1676 \pm 193$ \\
\hline NIC 0.3 - NAL 1 & $83.7 \pm 1.5$ & $9.8 \pm 1.7$ & $574 \pm 16$ & $8.6 \pm 2.2$ & $1680 \pm 131$ \\
\hline NIC 0.3 - NAL 3 & $81.6 \pm 1.5$ & $4.6 \pm 1.1^{*}$ & $588 \pm 18$ & $10.9 \pm 1.8$ & $1508 \pm 92$ \\
\hline
\end{tabular}

In total $n=16$ rats were included in the analyses, and data depict mean $\pm S E M$.

${ }^{*} p<0.05$ versus Vehicle-Vehicle control. 


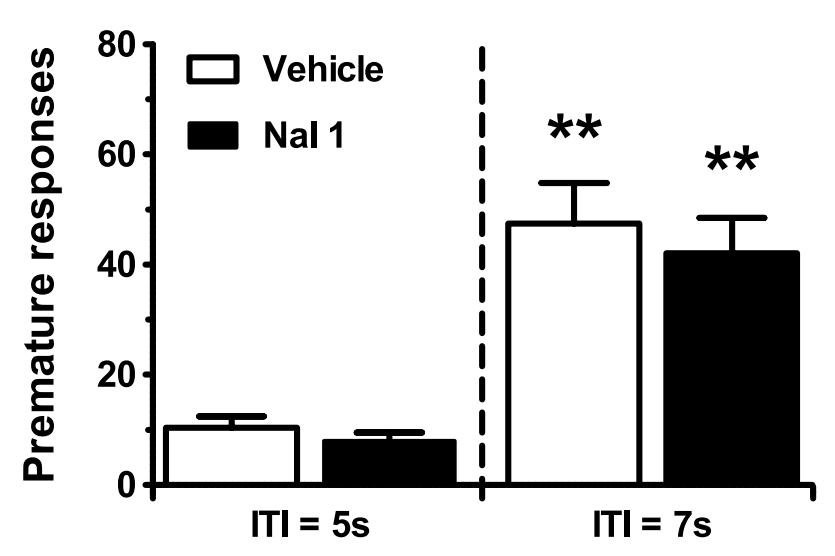

FIGURE 3 | Pretreatment with the opioid receptor antagonist naloxone does not affect motor impulsivity under long intertrial interval (ITI) conditions. Effects of naloxone (NAL) on the mean ( \pm SEM) number of premature responses made in the 5-CSRTT under conditions of normal or lengthened ITI. In total $n=16$ rats were included in the analyses. Drug doses are expressed as $\mathrm{mg} / \mathrm{kg}$. ${ }^{*} p<0.005$ versus respective Vehicle control.

Table 3 | Effects of the opioid receptor antagonist naloxone (NAL) on measures of attentional function, compulsivity, and motivation in the 5-CSRTT under conditions of normal or lengthened intertrial interval (ITI).

\begin{tabular}{|c|c|c|c|c|c|c|}
\hline Treatment (mg/kg) & ITI (s) & Accuracy (\%) & Perseverative responses & Correct response latency (ms) & Omissions & Feeder latency (ms) \\
\hline Vehicle & 5 & $83.9 \pm 2.4$ & $11.0 \pm 2.1$ & $626 \pm 23$ & $8.8 \pm 1.8$ & $1706 \pm 208$ \\
\hline NAL 1 & 5 & $86.7 \pm 2.6$ & $10.3 \pm 2.6$ & $632 \pm 20$ & $14.8 \pm 3.1$ & $2042 \pm 405$ \\
\hline Vehicle & 7 & $80.7 \pm 2.7^{+}$ & $6.6 \pm 1.7^{+}$ & $602 \pm 23$ & $10.3 \pm 1.8$ & $1686 \pm 259$ \\
\hline NAL 1 & 7 & $81.0 \pm 2.5^{+}$ & $5.3 \pm 1.2^{+}$ & $591 \pm 17$ & $13.4 \pm 2.2$ & $1476 \pm 86$ \\
\hline
\end{tabular}

In total $n=16$ rats were included in the analyses, and data depict mean $\pm S E M$.

${ }^{+} p<0.05$ versus respective $I T I=5$ s control.

prefrontal cortex (Kleijn et al., 2012). Because nicotine effects in the 5-CSRTT have been reported to be dopamine D2 receptordependent (van Gaalen et al., 2006), the current results showing that SR141716A prevents nicotine-induced premature responding are in line with the existence of a cannabinoid-dopamine interaction. The unexpected finding that SR141716A did not affect GBR 12909-induced premature responding, however, is not. The key to the cannabinoid-dopamine puzzle may be in the anatomical locus of the CB1 receptors involved in regulating 5-CSRTT behavior. It could be argued that the cannabinoid-dopamine interaction modulating motor impulsivity occurs at the cortical level. There, in contrast to nicotine and amphetamine (Nisell et al., 1996, 1997; Marshall et al., 1997; Dalley et al., 2002b; Kleijn et al., 2012), GBR 12909 does not robustly increase dopamine levels due to the low expression of the dopamine transporter in cortical areas (Elsworth et al., 1993; Freed et al., 1995; Sesack et al., 1998; Weikop et al., 2007). There is general consensus regarding the importance of the medial prefrontal cortex, and particularly the infralimbic cortex, in regulating motor impulsivity (Winstanley et al., 2006; Pattij and Vanderschuren, 2008; Dalley et al., 2011), and the effects of nicotine thereon (Tsutsui-Kimura et al., 2010). The role of dopamine in this brain area with respect to (drug-induced) motor impulsivity, however, has not been studied extensively. Available data actually suggest an important role for dopamine signaling within the nucleus accumbens rather than the medial prefrontal cortex in driving impulsive responding in the 5-CSRTT (Cole and Robbins, 1987, 1989; Puumala and Sirvio, 1998; Dalley et al., 2002a,b; Pattij et al., 2007b; Diergaarde et al., 2008). One recent study, however, suggests that dopamine signaling within another cortical brain region, the orbital frontal cortex, may be important in this respect as well (Winstanley et al., 2010b). Future studies using intracranial infusions should elucidate this issue.

It should be noted that psychostimulants such as amphetamine and nicotine can (in)directly affect many neurotransmitter systems including the norepinephric, serotonergic, and glutamatergic systems (McGinty, 1999; Rothman and Baumann, 2003; Berrendero et al., 2010). As none of these neurotransmitter systems were studied here, impulsivity-related, psychostimulantinduced release of endogenous cannabinoids may not require dopamine transmission. For instance, metabotropic glutamate receptor (mGluRs) subtypes $2 / 3$ and 5 have been implicated in the neural mechanisms underlying premature responding (Semenova and Markou, 2007; Liu et al., 2008; Counotte et al., 2011) as well as amphetamine- and nicotine-induced behaviors (Olive, 2009; Berrendero et al., 2010). Moreover, both mGluR2/3 and mGluR5 receptors have previously been reported to mediate the effects of CB1 receptor antagonists on amphetamine- and cocaine-induced behaviors (Xi et al., 2006; Tzavara et al., 2009; Ramiro-Fuentes et al., 2010). 


\section{INTERACTIONS BETWEEN THE DOPAMINE AND $\mu$-OPIOID RECEPTOR SYSTEMS ONLY MEDIATE MOTOR IMPULSIVITY UNDER SPECIFIC CONDITIONS}

The endogenous opioid system, and particularly the $\mu$-opioid receptor, is another neurotransmitter system that has previously been linked to impulsive behavior in humans and rodents (Kieres et al., 2004; Mitchell et al., 2007; Love et al., 2009; Pattij et al., 2009). The $\mu$-opioid receptor system is known to interact with both the dopamine (Di Chiara and Imperato, 1988; Hurd and Herkenham, 1992; Spanagel et al., 1992) and cannabinoid systems (Robledo et al., 2008; Parolaro et al., 2010). With regard to motor impulsivity as measured in the 5-CSRTT, it has previously been demonstrated that acute stimulation of $\mu$-opioid receptors, specifically those in the nucleus accumbens shell, increases premature responding, whereas $\mu$-opioid receptor antagonists reduce morphine- and amphetamine-induced premature responding (Wiskerke et al., 2011a). In that study, naloxone was also found to abolish GBR 12909-induced motor impulsivity, suggesting a dopamine-opioid link in regulating this type of impulsive behavior. The lack of effect of naloxone on nicotine-induced premature responding observed here, however, indicates that endogenous opioid systems do not mediate all dopamine-dependent forms of motor impulsivity. In view of previous findings regarding amphetamine-induced impulsivity (Cole and Robbins, 1987, 1989; Pattij et al., 2007b; Wiskerke et al., 2011a), the dopamine-opioid interaction may well be restricted to the mesolimbic dopamine pathway. Systemic nicotine administration acutely activates both the mesolimbic and mesocortical dopaminergic system (Nisell et al., 1996, 1997; Marshall et al., 1997). Unfortunately, it is as yet unknown which of those effects is relevant for display of impulsive behavior. Moreover, in vivo microdialysis studies thus far have only examined the role of $\mu$-opioid receptors in amphetamine- and nicotineinduced changes in mesolimbic dopamine release (Hooks et al., 1992; Maisonneuve and Glick, 1999; Schad et al., 2002; Berrendero et al., 2005). Alternatively, considering that all drugs of abuse have distinct effects on dopamine transmission (Sulzer, 2011), the way the dopaminergic system is activated (release quantity, phasic or tonic activity, burst or spike firing, etc.) may determine whether endogenous opioid systems are recruited to modulate premature responding. In this respect it is of interest that systemic challenges with psychostimulant drugs like GBR 12909 and particularly amphetamine have much stronger effects on extracellular dopamine levels as compared to nicotine (Di Chiara and Imperato, 1988; Leggio et al., 2009). Furthermore, since no selective $\mu-, \delta$-, or $\kappa$-opioid receptor antagonists were tested in this study, it cannot be ruled out that the observed nicotine effects result from $\delta$ - and/or $\kappa$-opioid receptor activation in addition to that of $\mu$-opioid receptors since all endogenous opioid peptide systems are activated following an acute challenge with nicotine (Berrendero et al., 2010; Hadjiconstantinou and Neff, 2011). Although naloxone at low doses preferentially blocks $\mu$-opioid receptors (Goldstein and Naidu, 1989; Eguchi, 2004), additional effects on $\delta$ - and/or $\kappa$-opioid receptors may have resulted in the absence of an overall effect on nicotine-induced premature responding. On the other hand, amphetamine also activates all endogenous opioid peptide systems (Hurd and Herkenham, 1992; Wang and McGinty, 1995; Olive et al., 2001), but only $\mu$-opioid receptors seem to be involved in amphetamine-induced motor impulsivity (Wiskerke et al., 2011a). Clearly, more research is required to elucidate the conditions under which dopamine-opioid interactions are recruited to modulate motor impulsivity.

\section{A RATE-DEPENDENT ROLE FOR CANNABINOID CB1 RECEPTORS, BUT NOT $\mu$-OPIOID RECEPTORS, IN REGULATING MOTOR IMPULSIVITY UNDER DRUG-FREE CONDITIONS}

In addition to the role of cannabinoids and opioids in druginduced motor impulsivity, we also evaluated their involvement in impulsive responding under drug-free conditions. The observation that naloxone did not affect premature responding under either high impulsivity (ITI $=7 \mathrm{~s}$ ) or baseline (ITI $=5 \mathrm{~s}$ ) conditions indicates that $\mu$-opioid receptors are not involved in regulating motor impulsivity under non-drug ("healthy") conditions. Instead, this neurotransmitter system can apparently be usurped by specific drugs of abuse such as amphetamine and opiates to increase motor impulsivity. In contrast, cannabinoid CB1 receptor antagonists have previously been shown to improve inhibitory control under drug-free conditions (Pattij et al., 2007a; de Bruin et al., 2011), with the effects becoming more apparent under conditions favoring higher levels of premature responding (Wiskerke et al., 2011b). Similarly, the dopamine D2 receptor antagonist eticlopride may attenuate premature responding under $7 \mathrm{~s}$, but not $5 \mathrm{~s}$ ITI conditions (Wiskerke and Pattij, unpublished observations). Thus, the anti-impulsivity effects of cannabinoid CB1 and dopamine D2 receptor antagonists may be rate-dependent and only be revealed under conditions of heightened cognitive load/inhibitory control demands, e.g., when the ITI duration is lengthened or following drug-induced increments in dopamine signaling.

Finally, it might be argued that effects on premature responding induced by drugs targeting the cannabinoid, dopaminergic, or opioid system are secondary to changes in other behavioral/cognitive processes. Several of the compounds used in previous studies from our laboratory to elucidate the role of cannabinoids, dopamine, and opioids in motor impulsivity also affected other behavioral parameters in the 5-CSRTT, particularly at higher doses (van Gaalen et al., 2006; Pattij et al., 2007a,b, 2009; Wiskerke et al., 2011a,b). Some of these parameters may reflect indices of food motivation, somatomotor activity, and/or timing behavior (Robbins, 2002). Similarly, in the current study particularly $3 \mathrm{mg} / \mathrm{kg}$ SR141716A increased omission rate and lengthened correct response latencies. Unlike drug-induced changes in motor impulsivity though, the reported drug effects on other behavioral parameters in the 5-CSRTT are usually modest and inconsistent between experiments, and do not correlate with the observed effects on premature responding.

\section{CONCLUSION}

This study did not fully elucidate the role of the endogenous cannabinoid, dopamine, and opioid systems in the regulation motor impulsivity, and the effects of drugs of abuse thereon. Nevertheless, the current data do underscore that all three neurotransmitter systems play an important role in this respect. Most likely, the cannabinoid, dopamine, and opioid systems interact 
in the regulation of (drug-induced) motor impulsivity. However, similar to what has previously been concluded for other reward-related behaviors such as social play behavior (Trezza et al., 2010), the current data suggest that this interaction is not simply triangular with reciprocal interactions between all three neurotransmitters. We hypothesize that the observed complexity arises from (1) the fact that two (indirectly heavily interacting) dopaminergic systems, the mesolimbic and mesocortical systems, subserve motor impulsivity, and (2) the fact that all drugs of abuse usurp distinct mechanisms to induce dopamine release, resulting in regionally (at the brain region as well as the synaptic level) and quantitatively quite distinct patterns of dopamine release. Thus, the spatial, temporal, and quantitative properties of impulsivityrelated dopamine release might determine the extent to which the endogenous cannabinoid and opioid systems are recruited. Future studies employing intracranial infusions are required to start elucidating this issue. From a clinical perspective, it is of interest that genotype for and the expression/availability of cannabinoid CB1, dopamine D2, and $\mu$-opioid receptors may determine one's level of impulsivity and vulnerability to impulsivity-related disorders such as Attention-Deficit/Hyperactivity Disorder and

\section{REFERENCES}

Baarendse, P. J., and Vanderschuren, L. J. (2012). Dissociable effects of monoamine reuptake inhibitors on distinct forms of impulsive behavior in rats. Psychopharmacology (Berl.) 219, 313-326.

Berrendero, F., Mendizabal, V., Robledo, P., Galeote, L., Bilkei-Gorzo, A., Zimmer, A., and Maldonado, R. (2005). Nicotine-induced antinociception, rewarding effects, and physical dependence are decreased in mice lacking the preproenkephalin gene. J. Neurosci. 25, 1103-1112.

Berrendero, F., Robledo, P., Trigo, J. M., Martin-Garcia, E., and Maldonado, R. (2010). Neurobiological mechanisms involved in nicotine dependence and reward: participation of the endogenous opioid system. $\mathrm{Neu}$ rosci. Biobehav. Rev. 35, 220-231.

Bickel, W. K., Odum, A. L., and Madden, G. J. (1999). Impulsivity and cigarette smoking: delay discounting in current, never, and ex-smokers. Psychopharmacology (Berl.) 146, 447-454.

Blondel, A., Sanger, D. J., and Moser, P. C. (2000). Characterisation of the effects of nicotine in the fivechoice serial reaction time task in rats: antagonist studies. Psychopharmacology (Berl.) 149, 293-305.

Broos, N., Schmaal, L., Wiskerke, J., Kostelijk, L., Lam, T., Stoop, N., Weierink, L., Ham, J., de Geus, E. J., Schoffelmeer, A. N., van den, B. W., Veltman, D. J., De Vries, T. J., Pattij, T., and Goudriaan, A. E. (2012). The relationship between impulsive choice and impulsive action: a crossspecies translational study. PLoS
ONE 7, e36781. doi:10.1371/journal.pone. 0036781

Buckholtz, J. W., Treadway, M. T., Cowan, R. L., Woodward, N. D., Li, R., Ansari, M. S., Baldwin, R. M., Schwartzman, A. N., Shelby, E. S., Smith, C. E., Kessler, R. M., and Zald, D. H. (2010). Dopaminergic network differences in human impulsivity. Science 329, 532.

Centonze, D., Bari, M., Di Michele, B., Rossi, S., Gasperi, V., Pasini, A., Battista, N., Bernardi, G., Curatolo, P., and MacCarrone, M. (2009). Altered anandamide degradation in attention-deficit/hyperactivity disorder. Neurology 72, 1526-1527.

Cole, B. J., and Robbins, T. W. (1987). Amphetamine impairs the discriminative performance of rats with dorsal noradrenergic bundle lesions on a 5-choice serial reaction time task: new evidence for central dopaminergic-noradrenergic interactions. Psychopharmacology (Berl.) 91, 458-466.

Cole, B. J., and Robbins, T. W. (1989). Effects of 6-hydroxydopamine lesions of the nucleus accumbens septi on performance of a 5-choice serial reaction time task in rats: implications for theories of selective attention and arousal. Behav. Brain Res. 33, 165-179.

Counotte, D. S., Goriounova, N. A., Li, K. W., Loos, M., Van der Schors, R. C., Schetters, D., Schoffelmeer, A. N., Smit, A. B., Mansvelder, H. D., Pattij, T., and Spijker, S. (2011). Lasting synaptic changes underlie attention deficits caused by nicotine exposure during adolescence. Nat. Neurosci. 14, 417-419.

substance abuse (Dalley et al., 2007; Ehlers et al., 2007; Centonze et al., 2009; Love et al., 2009; Buckholtz et al., 2010). Thus, the "state" of a patient's endogenous cannabinoid, dopamine, and opioid neurotransmitter systems might determine to what type of pharmacotherapy the patient will respond best. Importantly, impulsive behavior is thought to constitute several, largely independent behavioral modalities (Evenden, 1999; Winstanley et al., 2006; Pattij and Vanderschuren, 2008; Broos et al., 2012). Therefore, future research will also have to determine whether the current results on motor impulsivity generalize to other aspects of impulsivity. Similarly, previous studies have indicated that the effects of SR141716A and eticlopride, but not naloxone, on amphetamine-induced impulsivity generalize to impulsive choice, i.e., an intolerance to delayed gratification or delay aversion.

\section{ACKNOWLEDGMENTS}

This research was supported by a grant from the Dutch Top Institute Pharma (T5-107-1). The funders had no role in study design, data collection, and analysis, decision to publish, or preparation of the manuscript.

Counotte, D. S., Spijker, S., Van de Burgwal, L. H., Hogenboom, F., Schoffelmeer, A. N., De Vries, T. J., Smit, A. B., and Pattij, T. (2009). Longlasting cognitive deficits resulting from adolescent nicotine exposure in rats. Neuropsychopharmacology 34, 299-306.

Dalley, J. W., Everitt, B. J., and Robbins, T. W. (2011). Impulsivity, compulsivity, and top-down cognitive control. Neuron 69, 680-694.

Dalley, J. W., Fryer, T. D., Brichard, L., Robinson, E. S., Theobald, D. E., Laane, K., Pena, Y., Murphy, E. R., Shah, Y., Probst, K., Abakumova, I., Aigbirhio, F. I., Richards, H. K. Hong, Y., Baron, J. C., Everitt, B. J., and Robbins, T. W. (2007). Nucleus accumbens D2/3 receptors predict trait impulsivity and cocaine reinforcement. Science 315, 1267-1270.

Dalley, J. W., Theobald, D. E., Berry, D., Milstein, J. A., Laane, K., Everitt, B. J., and Robbins, T. W. (2005). Cognitive sequelae of intravenous amphetamine self-administration in rats: evidence for selective effects on attentional performance. Neuropsychopharmacology 30, 525-537.

Dalley, J. W., Theobald, D. E., Eagle, D. M., Passetti, F., and Robbins, T. W. (2002a). Deficits in impulse control associated with tonicallyelevated serotonergic function in rat prefrontal cortex. Neuropsychopharmacology 26, 716-728.

Dalley, J. W., Theobald, D. E., Pereira E. A., Li, P. M., and Robbins, T. W. (2002b). Specific abnormalities in serotonin release in the prefrontal cortex of isolation-reared rats measured during behavioural performance of a task assessing visuospatial attention and impulsivity. Psychopharmacology (Berl.) 164, 329-340.

de Bruin, N. M., Lange, J. H., Kruse, C. G., Herremans, A. H., Schoffelmeer, A. N., van Drimmelen, M., and De Vries, T. J. (2011). SLV330, a cannabinoid $\mathrm{CB}(1)$ receptor antagonist, attenuates ethanol and nicotine seeking and improves inhibitory response control in rats. Behav. Brain Res. 217, 408-415.

Di Chiara, G., and Imperato, A. (1988). Drugs abused by humans preferentially increase synaptic dopamine concentrations in the mesolimbic system of freely moving rats. Proc. Natl. Acad. Sci. U.S.A. 85, 5274-5278.

Diergaarde, L., Pattij, T., Poortvliet, I., Hogenboom, F., de Vries, W., Schoffelmeer, A. N., and De Vries, T. J. (2008). Impulsive choice and impulsive action predict vulnerability to distinct stages of nicotine seeking in rats. Biol. Psychiatry 63, 301-308.

Diergaarde, L., van Mourik, Y., Pattij, T., Schoffelmeer, A. N., and De Vries, T. J. (2011). Poor impulse control predicts inelastic demand for nicotine but not alcohol in rats. Addict. Biol. 17, 576-587.

Doran, N., Spring, B., and McChargue, D. (2007). Effect of impulsivity on craving and behavioral reactivity to smoking cues. Psychopharmacology (Berl.) 194, 279-288.

Eguchi, M. (2004). Recent advances in selective opioid receptor agonists and antagonists. Med. Res. Rev. 24, 182-212. 
Ehlers, C. L., Slutske, W. S., Lind, P. A., and Wilhelmsen, K. C. (2007). Association between single nucleotide polymorphisms in the cannabinoid receptor gene (CNR1) and impulsivity in southwest California Indians. Twin Res. Hum. Genet. 10, 805-811.

El Khoury, M. A., Gorgievski, V., Moutsimilli, L., Giros, B., and Tzavara, E. T. (2012). Interactions between the cannabinoid and dopaminergic systems: evidence from animal studies. Prog. Neuropsychopharmacol. Biol. Psychiatry. doi: 10.1016/j.pnpbp.2011.12.005.

Elsworth, J. D., Taylor, J. R., Berger, P., and Roth, R. H. (1993). Cocaine-sensitive and -insensitive dopamine uptake in prefrontal cortex, nucleus accumbens and striatum. Neurochem. Int. 23, 61-69.

Evenden, J. L. (1999). Varieties of impulsivity. Psychopharmacology (Berl.) $146,348-361$.

Fallon, J. H., and Moore, R. Y. (1978). Catecholamine innervation of the basal forebrain. IV. Topography of the dopamine projection to the basal forebrain and neostriatum. J. Comp. Neurol. 180, 545-580.

Fletcher, P. J., Rizos, Z., Noble, K., and Higgins, G. A. (2011). Impulsive action induced by amphetamine, cocaine and MK801 is reduced by $5-\mathrm{HT}(2 \mathrm{C})$ receptor stimulation and $5-\mathrm{HT}(2 \mathrm{~A})$ receptor blockade. Neuropharmacology 61, 468-477.

Freed, C., Revay, R., Vaughan, R. A., Kriek, E., Grant, S., Uhl, G. R., and Kuhar, M. J. (1995). Dopamine transporter immunoreactivity in rat brain. J. Comp. Neurol. 359, 340-349.

Goldstein, A., and Naidu, A. (1989). Multiple opioid receptors: ligand selectivity profiles and binding site signatures. Mol. Pharmacol. 36, 265-272.

Goto, Y., and Grace, A. A. (2007). The dopamine system and the pathophysiology of schizophrenia: a basic science perspective. Int. Rev. Neurobiol. 78, 41-68.

Grottick, A. J., and Higgins, G. A. (2000). Effect of subtype selective nicotinic compounds on attention as assessed by the five-choice serial reaction time task. Behav. Brain Res. 117, 197-208.

Hadjiconstantinou, M., and Neff, N. H. (2011). Nicotine and endogenous opioids: neurochemical and pharmacological evidence. Neuropharmacology 60, 1209-1220.

Higgins, G. A., Silenieks, L. B., Rossmann, A., Rizos, Z., Noble, K., Soko, A. D., and Fletcher, P. J.
(2012). The 5-HT(2C) receptor agonist lorcaserin reduces nicotine selfadministration, discrimination, and reinstatement: relationship to feeding behavior and impulse control. Neuropsychopharmacology 37, 1177-1191.

Hooks, M. S., Jones, D. N., Justice, J. B. Jr., and Holtzman, S. G. (1992). Naloxone reduces amphetamineinduced stimulation of locomotor activity and in vivo dopamine release in the striatum and nucleus accumbens. Pharmacol. Biochem. Behav. 42, 765-770.

Hurd, Y. L., and Herkenham, M. (1992). Influence of a single injection of cocaine, amphetamine or GBR 12909 on mRNA expression of striatal neuropeptides. Brain Res. Mol. Brain Res. 16, 97-104.

Jentsch, J. D., and Taylor, J. R. (1999). Impulsivity resulting from frontostriatal dysfunction in drug abuse: implications for the control of behavior by reward-related stimuli. Psychopharmacology (Berl.) 146, 373-390.

Kieres, A. K., Hausknecht, K. A., Farrar, A. M., Acheson, A., De Wit, H., and Richards, J. B. (2004). Effects of morphine and naltrexone on impulsive decision making in rats. Psychopharmacology (Berl.) 173, 167-174.

Kleijn, J., Wiskerke, J., Cremers, T. I., Schoffelmeer, A. N., Westerink, B. H., and Pattij, T. (2012). Effects of amphetamine on dopamine release in the rat nucleus accumbens shell region depend on cannabinoid CB1 receptor activation. Neurochem. Int. 60, 791-798.

Leggio, G. M., Cathala, A., Neny, M., Rouge-Pont, F., Drago, F., Piazza, P. V., and Spampinato, U. (2009). In vivo evidence that constitutive activity of serotonin $2 \mathrm{C}$ receptors in the medial prefrontal cortex participates in the control of dopamine release in the rat nucleus accumbens: differential effects of inverse agonist versus antagonist. J. Neurochem. 111, 614-623.

Liu, F., Grauer, S., Kelley, C., Navarra, R., Graf, R., Zhang, G., Atkinson, P. J., Popiolek, M., Wantuch, C., Khawaja, X., Smith, D., Olsen, M., Kouranova, E., Lai, M., Pruthi, F., Pulicicchio, C., Day, M., Gilbert, A., Pausch, M. H., Brandon, N. J., Beyer, C. E., Comery, T. A., Logue, S., Rosenzweig-Lipson, S., and Marquis, K. L. (2008). ADX47273 [S-(4-fluoro-phenyl)-\{3-[3-(4fluoro-phenyl)-[1,2,4]-oxadiazol5-yl]-piperidin-1-yl\}-methanone]: a novel metabotropic glutamate receptor 5 -selective positive allosteric modulator with preclinical antipsychotic-like and procognitive activities. J. Pharmacol. Exp. Ther. $327,827-839$

Love, T. M., Stohler, C. S., and Zubieta, J. K. (2009). Positron emission tomography measures of endogenous opioid neurotransmission and impulsiveness traits in humans. Arch. Gen. Psychiatry 66 1124-1134.

Maisonneuve, I. M., and Glick, S. D. (1999). (+/-)Cyclazocine blocks the dopamine response to nicotine. Neuroreport 10, 693-696.

Marshall, D. L., Redfern, P. H., and Wonnacott, S. (1997). Presynaptic nicotinic modulation of dopamine release in the three ascending pathways studied by in vivo microdialysis: comparison of naive and chronic nicotine-treated rats. J. Neurochem. 68, 1511-1519.

McGinty, J. F. (1999). Regulation of neurotransmitter interactions in the ventral striatum. Ann. N. Y. Acad. Sci. 877, 129-139.

Mitchell, J. M., Tavares, V. C., Fields, H. L., D'Esposito, M., and Boettiger, C. A. (2007). Endogenous opioid blockade and impulsive responding in alcoholics and healthy controls. Neuropsychopharmacology 32, 439-449.

Mitchell, S. H. (2004). Measuring impulsivity and modeling its association with cigarette smoking. Behav Cogn. Neurosci. Rev. 3, 261-275.

Nisell, M., Marcus, M., Nomikos, G. G. and Svensson, T. H. (1997). Differential effects of acute and chronic nicotine on dopamine output in the core and shell of the rat nucleus accumbens. J. Neural Transm. 104 $1-10$.

Nisell, M., Nomikos, G. G., Hertel, P., Panagis, G., and Svensson, T. H. (1996). Condition-independent sensitization of locomotor stimulation and mesocortical dopamine release following chronic nicotine treatment in the rat. Synapse 22 , 369-381.

Olive, M. F. (2009). Metabotropic glutamate receptor ligands as potential therapeutics for addiction. Curr. Drug Abuse Rev. 2, 83-98.

Olive, M. F., Koenig, H. N., Nannini, M. A., and Hodge, C. W. (2001). Stimulation of endorphin neurotransmission in the nucleus accumbens by ethanol, cocaine, and amphetamine. J. Neurosci. 21, RC184.

Olmstead, M. C., Ouagazzal, A. M., and Kieffer, B. L. (2009). Mu and delta opioid receptors oppositely regulate motor impulsivity in the signaled nose poke task. PLoS ONE 4, e4410. doi:10.1371/journal.pone.0004410

Parolaro, D., Rubino, T., Vigano, D., Massi, P., Guidali, C., and Realini, N. (2010). Cellular mechanisms underlying the interaction between cannabinoid and opioid system. Curr. Drug Targets 11, 393-405.

Pattij, T., Janssen, M. C., Schepers, I., Gonzalez-Cuevas, G., De Vries, T. J., and Schoffelmeer, A. N. (2007a). Effects of the cannabinoid $\mathrm{CB} 1$ receptor antagonist rimonabant on distinct measures of impulsive behavior in rats. Psychopharmacology (Berl.) 193, 85-96.

Pattij, T., Janssen, M. C., Vanderschuren, L. J., Schoffelmeer, A. N., and van Gaalen, M. M. (2007b). Involvement of dopamine D1 and D2 receptors in the nucleus accumbens core and shell in inhibitory response control. Psychopharmacology (Berl.) 191, 587-598.

Pattij, T., Schetters, D., Janssen, M. C., Wiskerke, J., and Schoffelmeer, A. N. (2009). Acute effects of morphine on distinct forms of impulsive behavior in rats. Psychopharmacology (Berl.) 205, 489-502.

Pattij, T., and Vanderschuren, L. J. (2008). The neuropharmacology of impulsive behaviour. Trends Pharmacol. Sci. 29, 192-199.

Perry, J. L., and Carroll, M. E. (2008). The role of impulsive behavior in drug abuse. Psychopharmacology (Berl.) 200, 1-26.

Pertwee, R. G. (2010). Receptors and channels targeted by synthetic cannabinoid receptor agonists and antagonists. Curr. Med. Chem. 17, 1360-1381.

Puumala, T., and Sirvio, J. (1998). Changes in activities of dopamine and serotonin systems in the frontal cortex underlie poor choice accuracy and impulsivity of rats in an attention task. Neuroscience 83, 489-499.

Ramiro-Fuentes, S., Ortiz, O., Moratalla, R., and Fernandez-Espejo, E. (2010). Intra-accumbens rimonabant is rewarding but induces aversion to cocaine in cocaine-treated rats, as does in vivo accumbal cannabinoid $\mathrm{CB} 1$ receptor silencing: critical role for glutamate receptors. Neuroscience 167, 205-215.

Robbins, T. W. (2002). The 5-choice serial reaction time task: behavioural pharmacology and functional neurochemistry. Psychopharmacology (Berl.) 163, 362-380.

Robledo, P., Berrendero, F., Ozaita, A., and Maldonado, R. (2008). Advances in the field of cannabinoid - opioid cross-talk. Addict. Biol. 13, 213-224. 
Rothman, R. B., and Baumann, M. H. (2003). Monoamine transporters and psychostimulant drugs. Eur. J. Pharmacol. 479, 23-40.

Schad, C. A., Justice, J. B. Jr., and Holtzman, S. G. (2002). Endogenous opioids in dopaminergic cell body regions modulate amphetamineinduced increases in extracellular dopamine levels in the terminal regions. J. Pharmacol. Exp. Ther. 300, 932-938.

Semenova, S., and Markou, A. (2007). The effects of the mGluR5 antagonist MPEP and the mGluR2/3 antagonist LY341495 on rats' performance in the 5-choice serial reaction time task. Neuropharmacology 52, 863-872.

Serrano, A., and Parsons, L. H. (2011). Endocannabinoid influence in drug reinforcement, dependence and addiction-related behaviors. Pharmacol. Ther. 132, 215-241.

Sesack, S. R., Hawrylak, V. A., Matus, C., Guido, M. A., and Levey, A. I. (1998). Dopamine axon varicosities in the prelimbic division of the rat prefrontal cortex exhibit sparse immunoreactivity for the dopamine transporter. J. Neurosci. 18, 2697-2708.

Solinas, M., Goldberg, S. R., and Piomelli, D. (2008). The endocannabinoid system in brain reward processes. Br. J. Pharmacol. 154, 369-383.

Spanagel, R., Herz, A., and Shippenberg, T. S. (1992). Opposing tonically active endogenous opioid systems modulate the mesolimbic dopaminergic pathway. Proc. Natl. Acad. Sci. U.S.A. 89, 2046-2050.

Sulzer, D. (2011). How addictive drugs disrupt presynaptic dopamine neurotransmission. Neuron 69, 628-649.
Tanda, G., Pontieri, F. E., and Di Chiara, G. (1997). Cannabinoid and heroin activation of mesolimbic dopamine transmission by a common mul opioid receptor mechanism. Science 276, 2048-2050.

Trezza, V., Baarendse, P. J., and Vanderschuren, L. J. (2010). The pleasures of play: pharmacological insights into social reward mechanisms. Trends Pharmacol. Sci. 31, 463-469.

Tsutsui-Kimura, I., Ohmura, Y., Izumi, T., Yamaguchi, T., Yoshida, T., and Yoshioka, M. (2010). Nicotine provokes impulsive-like action by stimulating alpha4beta 2 nicotinic acetylcholine receptors in the infralimbic, but not in the prelimbic cortex. Psychopharmacology (Berl.) 209, 351-359.

Tzavara, E. T., Degroot, A., Wade, M. R., Davis, R. J., and Nomikos, G. G. (2009). CB1 receptor knockout mice are hyporesponsive to the behavior-stimulating actions of damphetamine: role of mGlu5 receptors. Eur. Neuropsychopharmacol. 19, 196-204.

Ungerstedt, U. (1971). Stereotaxic mapping of the monoamine pathways in the rat brain. Acta Physiol. Scand. Suppl. 367, 1-48.

van Gaalen, M. M., Brueggeman, R. J., Bronius, P. F., Schoffelmeer, A. N., and Vanderschuren, L. J. (2006). Behavioral disinhibition requires dopamine receptor activation. Psychopharmacology (Berl.) 187, 73-85.

Verdejo-Garcia, A., Lawrence, A. J., and Clark, L. (2008). Impulsivity as a vulnerability marker for substanceuse disorders: review of findings from high-risk research, problem gamblers and genetic association studies. Neurosci. Biobehav. Rev. 32, 777-810.

Wang, J. Q., and McGinty, J. F. (1995). Alterations in striatal zif/268, preprodynorphin and preproenkephalin mRNA expression induced by repeated amphetamine administration in rats. Brain Res. 673, 262-274.

Weikop, P., Kehr, J., and Scheel-Kruger, J. (2007). Reciprocal effects of combined administration of serotonin, noradrenaline and dopamine reuptake inhibitors on serotonin and dopamine levels in the rat prefrontal cortex: the role of 5-HT1A receptors. J. Psychopharmacol. (Oxford) 21, 795-804.

Winstanley, C. A. (2011). The utility of rat models of impulsivity in developing pharmacotherapies for impulse control disorders. Br. J. Pharmacol. 164, 1301-1321.

Winstanley, C. A., Eagle, D. M., and Robbins, T. W. (2006). Behavioral models of impulsivity in relation to ADHD: translation between clinical and preclinical studies. Clin. Psychol. Rev. 26, 379-395.

Winstanley, C. A., Olausson, P., Taylor, J. R., and Jentsch, J. D. (2010a). Insight into the relationship between impulsivity and substance abuse from studies using animal models. Alcohol. Clin. Exp. Res. 34, 1306-1318.

Winstanley, C. A., Zeeb, F. D., Bedard, A., Fu, K., Lai, B., Steele, C., and Wong, A. C. (2010b). Dopaminergic modulation of the orbitofrontal cortex affects attention, motivation and impulsive responding in rats performing the five-choice serial reaction time task. Behav. Brain Res. 210, 263-272.

Wiskerke, J., Schetters, D., van Es, I., van Mourik, Y., den Hollander, B. R., Schoffelmeer, A. N., and Pattij, T. (2011a). mu-Opioid receptors in the nucleus accumbens shell region mediate the effects of amphetamine on inhibitory control but not impulsive choice. J. Neurosci. 31, 262-272.

Wiskerke, J., Stoop, N., Schetters, D., Schoffelmeer, A. N., and Pattij, T. (2011b). Cannabinoid CB1 receptor activation mediates the opposing effects of amphetamine on impulsive action and impulsive choice. PLoS ONE 6, e25856. doi:10.1371/journal.pone.0025856

Xi, Z. X., Gilbert, J. G., Peng, X. Q., Pak, A. C., Li, X., and Gardner, E. L. (2006). Cannabinoid $\mathrm{CB} 1$ receptor antagonist $\mathrm{AM} 251$ inhibits cocaine-primed relapse in rats: role of glutamate in the nucleus accumbens. J. Neurosci. 26, 8531-8536.

Conflict of Interest Statement: The authors declare that the research was conducted in the absence of any commercial or financial relationships that could be construed as a potential conflict of interest.

Received: 13 April 2012; paper pending published: 04 May 2012; accepted: 20 May 2012; published online: 11 June 2012.

Citation: Wiskerke J, van Mourik Y, Schetters D, Schoffelmeer ANM and Pattij $T$ (2012) On the role of cannabinoid $C B 1$ - and $\mu$-opioid receptors in motor impulsivity. Front. Pharmacol. 3:108. doi: 10.3389/fphar.2012.00108

This article was submitted to Frontiers in Neuropharmacology, a specialty of Frontiers in Pharmacology.

Copyright (c) 2012 Wiskerke, van Mourik, Schetters, Schoffelmeer and Pattij. This is an open-access article distributed under the terms of the Creative Commons Attribution Non Commercial License, which permits non-commercial use, distribution, and reproduction in other forums, provided the original authors and source are credited. 